\title{
The Effect of Authentic Versus Non-Authentic Texts on Upper Intermediate Iranian EFL Learners' Vocabulary Retention
}

\author{
Shirin Nematollahi ${ }^{1} \&$ Mojtaba Maghsoudi ${ }^{2}$ \\ ${ }^{1}$ Islamic Azad University, Arak Branch, Iran \\ ${ }^{2}$ Farhangian University, Iran \\ Correspondence: Shirin Nematollahi, Islamic Azad University, Arak Branch, Iran. E-mail: \\ shirin1983_n@yahoo.com
}

Received: July 27, 2015 Accepted: November 18, 2015 Online Published: November 22, 2015

doi:10.5539/elt.v8n12p112 URL: http://dx.doi.org/10.5539/elt.v8n12p112

\begin{abstract}
In this current study the researchers have tried to investigate the possible effect of authentic and non-authentic texts on Iranian EFL learners' vocabulary retention. Despite the great deal of studies conducted in the area of EFL/ESL learning, the effect of authentic versus non-authentic texts have almost gained little attention and been underresearched. To this end and to fill this gap, the sample selection was done by a proficiency PET (Preliminary English Test). So, out of 114 EFL learners, 74 learners both male and female were chosen as the participants to take part in the research. The findings from repeated measurement test revealed that authentic versus non-authentic texts and also the learners' gender have no impact on EFL learners' vocabulary retention ability.
\end{abstract}

Keywords: authentic text, non-authentic text, vocabulary retention

\section{Introduction}

\subsection{Importance of Vocabulary Retention}

Many researchers consider vocabulary acquisition to be the single most important aspect of second-language learning (Knight, 1994). It is argued that, in order to develop linguistic abilities, second-language (L2) readers need to reach a certain level of vocabulary threshold (Brisbois, 1995; Geva \& Clifton, 1994; Kim, 1995; Lomicka, 1998). It was shown that reading comprehension is tightly connected to vocabulary knowledge (Laufer, 1997; Adams, 2000). Stahl (1983, p. 33) describes the relationship between reading comprehension and vocabulary knowledge as "one of the best documented relationships in reading research". Vocabulary knowledge is fundamental to reading comprehension; one cannot understand text without knowing what most words mean (Nagy, 1988). Adams (2000) explored the relationship between reading comprehension, vocabulary, and fluency and found that word knowledge was important to comprehend, as was fluency. This correlation between students' vocabulary and students' comprehension of what they read (Gersten \& Geva, 2003) led many researchers to believe that "a reader's general vocabulary knowledge is the best predictor of how well that reader can understand text" (Anderson \& Freebody, 1981, p. 3). Stahl (2003), who called the relationship between reading and vocabulary "robust," argues that vocabulary knowledge has been consistently been the "foremost predictor of a text's difficulty" (p. 241). Laufer (1997) argues that students who have a knowledge of 3000 word families or 5000 lexical words can achieve a reading score of $56 \%$, those who have a knowledge of 4000 word families or 6400 lexical words can achieve a reading score of $63 \%$, while an increase to 6000 words families or 9600 lexical words will result in a score of $77 \%$. Other studies (Groot, 1994; Hazenberg \& Hulstijn, 1996; Hirsh \& Nation, 1992; Laufer, 1989, as cited in Groot, 2000) found that, in order for second-language (L2) readers to adequately understand academic texts, they must be familiar with more than $90 \%$ of the words used. This great need for vocabulary explains the difficulty that foreign-language learners face when reading texts in the target language.

Laufer (1997) refers to L2 readers' struggle with vocabulary while reading L2 as "the lexical plight." It is no surprise that a majority of students studying a foreign language and their teachers cite vocabulary as their number one priority (Knight, 1994).

\subsection{Authentic Versus Non-authentic Materials}

Many teachers involved in foreign language teaching have discussed the use of authentic materials in an EFL classroom in recent years. Some researchers insist that the English presented in the classroom should be authentic, 
not produced for instructional purposes. Generally, what this means is that materials which involve language naturally occurring as communication in native-speaker contexts of use, or rather those selected contexts where Standard English is the norm: real newspaper reports, for example, real magazine articles, real advertisements, cooking recipes, horoscopes, etc.

Martinez (2002) listed following pluses and minuses:

Advantages:

- $\quad$ Students are exposed to real language

- $\quad$ There is factual acquisition from most of them

- Textbooks do not contain inaccurate language

- $\quad$ Authentic materials may be inspirational for some students

- $\quad$ One piece of text may be used for various activities and tasks

- $\quad$ There is a wide choice of styles, genres and formality in authentic texts

- $\quad$ They can make students eager to read for pleasure

Disadvantages:

- $\quad$ Authentic texts may be difficult to understand because of a culture gap

- $\quad$ The vocabulary may be not exactly what the students need

- $\quad$ They are rather difficult for beginners

- $\quad$ Preparation of the texts and activities is often demanding and time consuming

- $\quad$ Accents and dialects are varying so muchin listening

- $\quad$ The materials may become outdated quickly (news)

On the other hand a non-authentic material in language teaching terms is one that has been written especially for language students. Such materials sometimes concentrate on the language EFL teachers wish to teach. The obviously artificial nature of the language of non-authentic texts makes it very unlike anything that learners are likely to encounter in real life. Whilst some may claim that non-authentic text is useful for teaching structures, it is not recommended to be used to teach reading or listening skills.

Hulstijn et al. (1996) believe that "If one does not know the meaning of the words occurring in a text, understanding is severely hampered" (p. 54). Hence, learners should pay attention to the words as a part of a message and individual words as well (Nation, 2001). Besides in learning a new language using applicable strategies and appropriate material plays an important role in language learning. Studies on the acquisition of a second language have shown that using authentic material motivates learners in learning the new language. On the other hand, because learners are not familiar with L2 Culture, religion, customs, taboos and ..., learning the new vocabulary seems intangible and therefore de-motivating. Furthermore, language is defined as device for communication so, as long as language learners have customs, culture, religion and taboos in common in their own community using non-authentic materials also seems inevitable.

The other reason this study is important is that the findings of this study will be helpful to teachers who are looking for appropriate ways to help students increase the size of their word mastery and facilitate their reading comprehension.

To ensure whether authenticity of the material has had any possible effect on the vocabulary retention of upper-intermediate Iranian EFL learners, we were in need of a yardstick to analyze the learner's performance in this regard.

\section{Literature Review}

\subsection{Authenticity and Language Learning}

The use of authentic materials in language education has a long, yet, not coherent history. Mishan (2005) divides the language teaching methods preceding and eventually leading to the authenticity-centered approach into three groups: communicative approaches, materials focused approaches and humanistic approaches.

Mishan (ibid) explains that the core idea embraced by the communicative approaches is: "a means of communication can only be learned by using it for this purpose". In addition, Mishan (ibid.) argues that communicative approaches were used as early as the colonial times when a clear need emerged to communicate 
with people from other cultures. She continues by explaining that much of the language learning and teaching that took place at that time can be regarded as "authentic in spirit" as language learning had a clear communicative goal and occurred through direct contacts with native speakers in non-classroom settings and without any specific learning materials.

What is nowadays known as communicative language teaching (CLT) has its roots in the language teaching methodologies of the 1970s (Mishan, 2005 and Gilmore, 2007).

What can be seen as a specific ignition to CLT was Chomsky's (1965) distinction between language competence and language performance. Chomsky (ibid) used the term language competence to refer to the speaker's or hearer's knowledge of the language while language performance was used to refer to the actual use of language. This definition would contribute to the construction of the term communicative competence, which would function as the cornerstone of CLT (Mishan, 2005). In addition, laying emphasis on communication over form, CLT created new pedagogical reasoning for the use of authentic materials in foreign language education (Mishan, ibid). Berardo (2006) argues that authenticity is a central concept in CLT as learners ought to be exposed to the same linguistic variation as native speakers. Khaniya (2006) summarizes the view by arguing that authentic materials are essential in a communicative language class since the use of artificial texts tells us very little about the students' actual abilities to communicate outside the classroom as they do not represent a reality of language use.

The materials-focused approaches which dominated the 20thcentury adapt several views on language acquisition (Mishan, 2005). The approach has along history in foreign language teaching methodologies with proof of the use of authentic materials found as early as the $9^{\text {th }}$ century in England (Mishan, 2005). By medieval time the teaching method most commonly used was the "scholastic method" which consisted of learning the alphabet and memorizing sequences by heart. As there was no specific book designed for language teaching, authentic texts, such as prayer books, were often used (Mishan, 2005).

As an example of the materials-focused approaches, Mishan (2005) mentions the inductive method that was introduced in the 1890s by Sweet (1899) who is regarded as one of the first who saw a pedagogical potential in the use of authentic materials in language teaching (Gilmore, 2007). Sweet (1899) suggested that grammar should be taught trough texts that could be examined and analyzed by learners. Mishan (2005) concludes that Sweet's ideas can be regarded as strikingly modern since some of his ideas are still known and used to this day.

As can be seen, the use of authentic materials and authenticity in language learning started to gain ground in language pedagogy very early in history, however, the early part of the20thcentury was defined by a blossoming of a variety of teaching methods such as the oral method, the audio lingual method, the situational approach and the direct method, which applied language learning materials that concentrated on the linguistic aspects of language and were specifically structured for language learning purposes (Mishan, 2005; Gilmore, 2007). According to Mishan (2005), this period of time can be seen as the foundation to the still existing dependency on textbooks, the choice of teaching material for the majority of teachers.

\section{Method}

\subsection{Participants}

In the present study were 74 adult Iranian EFL learners with the age within the range of 17 to 32 years participated. This sample comprised of 44 female and 30 male EFL learners at the upper-intermediate level+ in studying at Aryanpour English institute in Tehran and Kishair English Institute in Esfahan.

In the present study, the sample selection was done by a proficiency test. So, a large sample of 114 upper-intermediate EFL learners was/were selected and a piloted language proficiency test, sample Preliminary English Test (2010), was administered to them. Following the PET administration and in order to have a homogeneous sample, 74 EFL learners whose scores fell within the range of one standard deviation above and below the sample mean were selected as the participants of this research.

It would be worthy to mention that, 15 upper-intermediate EFL learners who had the same characteristics and language proficiency level as those of the target sample consisted of 6 males and 9 females formed the pilot group.It should be also mentioned that the pilot group participants were EFL students at the same language institutes.

\subsection{Instruments}

In order to conduct this thesis, the following instruments were used:

\section{A) The six authentic and non-authentic texts}

Three non-authentic texts were selected from a vocabulary practice book named 'English Vocabulary in Use, 
Upper-intermediate, Third Edition' by MichealMaccarthy and Felicity O'Dell and three authentic texts were selected from a web site which belongs to TIME FOR KIDS magazine 'www.timeforkids.com'. All six texts were given in the form of copies to both groups.

\section{B) Language proficiency test (PET)}

First the sample PET was piloted. The Preliminary English Testpublished by Cambridge English for Speakers of Other Languages (ESOL, 2010). In the piloting phase, the reliability came out to be 0.83 . Then the sample PET was practically used for the participants'homogenization of the study in terms of their English proficiency. In fact, EFL learners whose scores fell within the range of one standard deviation above and below the sample mean were chosen as the subjects to take part in the research. The reliability of the test in this phase was 0.71 .

\section{C) The vocabulary test}

A 30-item vocabulary test, which was designed and piloted by the researcher based on the materials of the treatment, comprised of 6 matching, 12 multiple-choice, and 12 fill-in-the-blank items (for which the students were to select the appropriate word from a list and write it down in the blank), each of the items tested one single vocabulary. The allotted time for doing the test was 30 minutes (one minute for each item). In order to ensure the reliability of the vocabulary test, at the piloting stage it was administered to 15 students of the similar groups taking part in the study. Based on the data gathered, the reliability was calculated to be 0.8 . The present researcher also asked two experts in same field of the study to assess the test in terms of its effectiveness. The experts' feedback confirmed the content validity of the current research.

\section{D) The 30-word list}

The main goal of the word list which contained as the same vocabularies the vocabulary test was to make sure that the students would not choose the correct answer in the test by chance. A vocabulary checklist that contained the same vocabularies as the vocabulary test in which, the participants were obliged to write a synonym or a definition in either $\mathrm{L} 1$ or $\mathrm{L} 2$.

\subsection{Procedure}

To attain the objectives of this present research the following procedures were conducted by the researcher:

After reviewing the related literature in the field of second and foreign language authentic and non-authentic text use and vocabulary retention, the first phase of the study was the primitive study in order to find the most suitable six authentic and non-authentic texts.

In the second phase, for homogenizing texts with upper-intermediate students, the texts readability indices indicated. Readability is the ease in which text can be read and understood. Various factors to measure readability have been used, such as "speed of perception," "perceptibility at a distance," "perceptibility in peripheral vision," "visibility," "the reflex blink technique," "rate of work" (e.g., speed of reading), "eye movements," and "fatigue during reading (Wikipedia the free encyclopedia). All six texts had a readability index between 9 to 12 which is acceptable for upper-intermediate level.

The third phase of the study was the pilot phase in which 15 upper-intermediate students with same characteristics to the target sample took all the assessment instruments consisting of the sample PET which is used for homogenization, and a 30-item vocabulary test. At first, for the vocabulary tests, the researcher chose 50 words from the target texts and gave the list of these words to the pilot group to mark the known words by providing a synonym or the meaning in either L1 or L2. It was proved that 17 words were known by $60 \%$ of the studentsand therefore they were discarded. To equalize the number of words of the vocabulary test from both authentic and non-authentic texts three more words discarded, so number of words reduced to 30 . In the next stage, based on the remaining 30 words, a vocabulary test was designed and piloted with the same group. After running item analysis the results showed that there was not any malfunctioning item. There was no item which was answered correctly by $60 \%$ of the participants, and even no item was answered by two EFL learners of the piloting group and the reliability of the test was 0.8 , so the test did not change. Therefore, the researcher came up with a 30-item vocabulary test which was used for pre-test, post-test and delayed post-test.

The fourth phase comprised administration of the piloted tests of the target students for the purpose of participant selection. The piloted sample PET (2010) was administered to 114 male and female students at Aryanpour English institute in Tehran and kishair English institute in Esfahan in order to choose the participants who held the same level of language proficiency. Out of the 114 students, those whose scores were 1SD below the mean were taken as Low and those whose scores were 1SD above the mean as High level, making 74 students in total.

In the fifth phase of the study the 74 homogeneous students took part in the piloted 30-item teacher-made 
vocabulary test (pre-test) which contains the target vocabularies. Thirty target vocabularies which participants did not know at the onset of the study were presented in two forms, one a vocabulary checklist in which the participants were supposed to write a synonym or a definition in L1 or L2, and the other in the form of a vocabulary retention test with multiple choice, matching items and fill-in-the-blank. To check to what extent the participants were able to retain the vocabularies in both decontextualized (through the checklist) and contextualized (through the vocabulary test) ways, the two forms for the vocabulary test was devised.

The administration of the vocabulary list took 20 minutes and it took 30 minutes to administer the vocabulary test. In order to prevent the students' fatigue, a 10 minute gap was allowed between the two tests. Each participant was awarded a score of one for each vocabulary that he/she had both selected the correct response from among the alternatives on the vocabulary test and provided the correct synonym or definition in Persian or English on the checklist determiningthat vocabulary's retention. If just one of these were correct, the participant probably have guessed the answer on the multiple choice test and would receive a score of zero on that vocabulary indicating lack of retention.

In the sixth phase, to arrive at the pre assumed results, giving a relative treatment was needed.

Therefore, the present researcher provided the learners with the following treatment type:

Both female and male EFL learners were exposed to target vocabularies' dictionary meaning also the researcher used some vocabulary teaching strategies such as butchering, surrounding and brain storming to teach the new words. Besides, all six texts were read aloud and learners repeated the correct form of the word's pronunciation.

The treatment was done during three sessions. In each session two texts; one authentic and one non-authentic; were taught. Between teachings of these two texts in each session, participants had a break in order to avoid learner's fatigue to influence EFL learners' vocabulary learning. Also, the allotted time for each text and its five unknown vocabularies was 30 minutes and the time duration was enough for all six texts because the readability and length of texts were close together and proper for upper-intermediate level.

The seventh phase has been just the next session after finishing the treatment. The post-test which was the same as the pre-test was administered to all participants including both female and male students from both institutes.

Two weeks after the completion of the treatment, the post-delayed-test was administered to all participants which were again the same vocabulary test in addition to the 30 -word list. The students were not told that they would take a vocabulary retention delayed post-test and the interval of two weeks was chosen because less than this time the students might use their short-term memory to answer the questions and in more than two weeks further learning may occur.

\subsection{Data Analysis}

In order to analyze the obtained data, the researcher computed them by means of the statistical package SPSS. The kinds of analyses that were used included Mean Scores, Standard Deviation, and Repeated Measures of Variance.

\section{Results}

To investigate whether the gender of Iranian upper-intermediate EFL learners has any Impact on their vocabulary retention regarding authentic versus non-authentic text and also, whether the authenticity of the texts has any effect on their vocabulary retention the data were analyzed based on Repeated Measures of variance(GLMRM) because of the existence of within subject factors in three levels (pre-test, post-test and delayed post-test). Test scores of the three vocabulary tests (pre-test, post-test and delayed post-test) in authentic and non-authentic texts from male and female EFL learners have been measured.

In order to report the descriptive statistics of the variables a table 1 is shown below, in which the mean and standard deviation of the vocabulary tests ( pre-test, post-test and delayed post-test) for both male and female participants is shown. 
Table 1. Descriptive statistics

\begin{tabular}{|c|c|c|c|c|c|}
\hline & Gender & Text & Mean & Std. Deviation & $\mathrm{N}$ \\
\hline & & Auth & .79 & .975 & 14 \\
\hline & Male & NonAuth & 1.06 & 1.526 & 16 \\
\hline & & Total & .93 & 1.285 & 30 \\
\hline & & Auth & .77 & 1.066 & 22 \\
\hline \multirow[t]{9}{*}{ PreTest } & Female & NonAuth & .77 & 1.020 & 22 \\
\hline & & Total & .77 & 1.031 & 44 \\
\hline & & Auth & .78 & 1.017 & 36 \\
\hline & Total & NonAuth & .89 & 1.247 & 38 \\
\hline & & Total & .84 & 1.135 & 74 \\
\hline & & Auth & 11.36 & 2.240 & 14 \\
\hline & Male & NonAuth & 12.00 & 2.422 & 16 \\
\hline & & Total & 11.70 & 2.322 & 30 \\
\hline & & Auth & 11.77 & 1.974 & 22 \\
\hline \multirow[t]{9}{*}{ PostTest } & Female & NonAuth & 11.55 & 1.595 & 22 \\
\hline & & Total & 11.66 & 1.778 & 44 \\
\hline & & Auth & 11.61 & 2.060 & 36 \\
\hline & Total & NonAuth & 11.74 & 1.968 & 38 \\
\hline & & Total & 11.68 & 2.001 & 74 \\
\hline & & Auth & 10.71 & 2.525 & 14 \\
\hline & Male & NonAuth & 11.44 & 2.851 & 16 \\
\hline & & Total & 11.10 & 2.683 & 30 \\
\hline & & Auth & 10.95 & 2.478 & 22 \\
\hline \multirow[t]{5}{*}{ DelayTest } & Female & NonAuth & 10.41 & 2.197 & 22 \\
\hline & & Total & 10.68 & 2.331 & 44 \\
\hline & & Auth & 10.86 & 2.463 & 36 \\
\hline & Total & NonAuth & 10.84 & 2.510 & 38 \\
\hline & & Total & 10.85 & 2.470 & 74 \\
\hline
\end{tabular}

Auth= Authentic.

NonAuth $=$ Non-authentic.

In Table 1, mean and standard deviation of all pre-test scores in vocabularies of authentic texts of male EFL learners are 0.79 and 0.975 respectively and in vocabularies of non-authentic texts are 1.06 and 1.526. Furthermore, mean and standard deviation of all post-test scores in vocabularies of authentic texts of male participants are 11.36 and 2.240 respectively and in vocabularies of non-authentic texts are 12.00 and 2.422. Also mean and standard deviation of all delayed post-test scores of vocabularies of authentic texts of male learners are 10.71 and 2.525 and in non-authentic texts are 11.44 and 2.851 respectively.

Important assumption of repeated measures of variables is that the variance-covariance of the dependent variables must be spherical. Mauchly'ssphericity test results on the variance-covariance of the dependent variables are summarized in the following table: 
Table 2. Mauchly's test of sphericity

Measure: Teaching

\begin{tabular}{lllcll}
\hline Within Subjects Effect & Mauchly's W & Approx. Chi-Square Df & Sig. & Epsilon \\
\hline Time & .458 & 53.869 & 2 & .000 & .684
\end{tabular}

Tests the null hypothesis that the error covariance matrix of the orthonormalized transformed dependent variables is proportional to an identity matrix.

Due to the small amount of the significance level ( $\operatorname{sig}=0.000)$ which is shown in Table 2, it is concluded that the assumption of sphericity of variance-covariance matrix of dependent variables in not set. Hence, for the analysis of the results, in order to correct degrees of freedom, results of huynh-feldt correction factors should be used.

Variance analysis test with repeated measures is sensitive in relation with covariance matrix equivalence observed of variables among male and female subjects and authentic versus non-authentic texts. So, at first M, Box test table is used to evaluate this hypothesis:

Table 3. Box's test of equality of covariance matrices

\begin{tabular}{cc}
\hline Box's M & 20.514 \\
\hline F & 1.046 \\
df1 & 18 \\
df2 & 12595.466 \\
Sig. & .403 \\
\hline
\end{tabular}

Tests the null hypothesis that the observed covariance matrices of the dependent variables are equal across groups.

Regarding the statistic figures of Fisher test $\mathrm{F}(1.046)$ and also the small figure of significance level (sig=0.403) it is concluded from the above table that there is no reason to reject the null hypothesis "covariance matrix equivalence observed of dependent variables among male and female subjects and text types of authentic and non-authentic", at any error level. This means that observed covariance matrix of dependent variables among male and female participants and text types of authentic and non-authentic, is equal at any error level.

In order to, evaluate the effect significance of each independent variable in the model, the following table containing $\mathrm{F}$ test statistic results, with modified free level of huynh-feldt, because of applying variance-covariance matrices spherical figure of dependent variables, is used. That is to evaluate the main effects of the dependent variable within-subjects and their interactive impacts on dependent variable (within-subjects).

Table 4. Tests of within-subjects effects

Measure: Teaching

\begin{tabular}{lllllll}
\hline Source & & Type III Sum of Squares & Df & Mean Square & F & Sig. \\
\hline Time & Huynh-Feldt & 5178.613 & 1.368 & 3785.588 & 1161.512 & .000 \\
Time * Text & Huynh-Feldt & .127 & 1.368 & .093 & .028 & .926 \\
Time * Gender & Huynh-Feldt & 1.285 & 1.368 & .939 & .288 & .665 \\
Time * Gender * Text & Huynh-Feldt & 2.216 & 1.368 & 1.620 & .497 & .540 \\
Error(Time) & Huynh-Feldt & 312.096 & 95.759 & 3.259 & & \\
\hline
\end{tabular}

The analysis of the data which is shown in this table shows that regarding authentic and non-authentic texts in the second row, the significance level is 0.9 , which is greater than 0.05 . Whenever the significance level is greater than 0.05 , the null hypothesis is accepted. Therefore there is no significant difference between authentic and 
non-authentic texts in improving Iranian EFL learners' vocabulary retention. In the fourth row as you can see, the effect of EFL learners' gender on their vocabulary retention ability regarding authentic and non-authentic texts were analyzed. According to the last column of this table the significance level is 0.5 . as you see this is again greater than $0.05 \mathrm{so}$, the null hypothesis is accepted. As a matter of fact, the Iranian EFL learner's gender has no impact on their vocabulary retention ability regarding authentic versus non-authentic texts.

Although both two null hypotheses are accepted, but to see whether the treatment had any effect on EFL learners' vocabulary retention, learner scores in pre-test, immediate post-test and delayed post-test were analyzed.

Table 5. Pairwise comparisons

Measure: Teaching

\begin{tabular}{lllllll}
\hline (I) Time & $(\mathrm{J})$ Time & \multicolumn{2}{l}{ Mean Difference (I-J) } & Std. Error Sig. & & \multicolumn{2}{l}{ 95\% Confidence Interval for Difference } \\
\cline { 5 - 6 } & & & & & Lower Bound & Upper Bound \\
\hline 1 & 2 & -10.820 & .263 & .000 & -11.465 & -10.176 \\
& 3 & -10.030 & .315 & .000 & -10.802 & -9.259 \\
2 & 1 & 10.820 & .263 & .000 & 10.176 & 11.465 \\
& 3 & .790 & .141 & .000 & .444 & 1.136 \\
3 & 1 & 10.030 & .315 & .000 & 9.259 & -.444
\end{tabular}

Regarding the reported significance level column in the above table, it is considered that significance level for the difference of learning and retaining words among pretest, post-test and delayed test in all mutual comparisons is less than 0.05 ( $\mathrm{Sig}=0.000)$. Therefore, it is concluded that there is a meaningful significant difference between dependent means of learning and retaining vocabulary among independent variable levels (Figure 1).

For better understanding of the matter, the following graphic figure is presented:

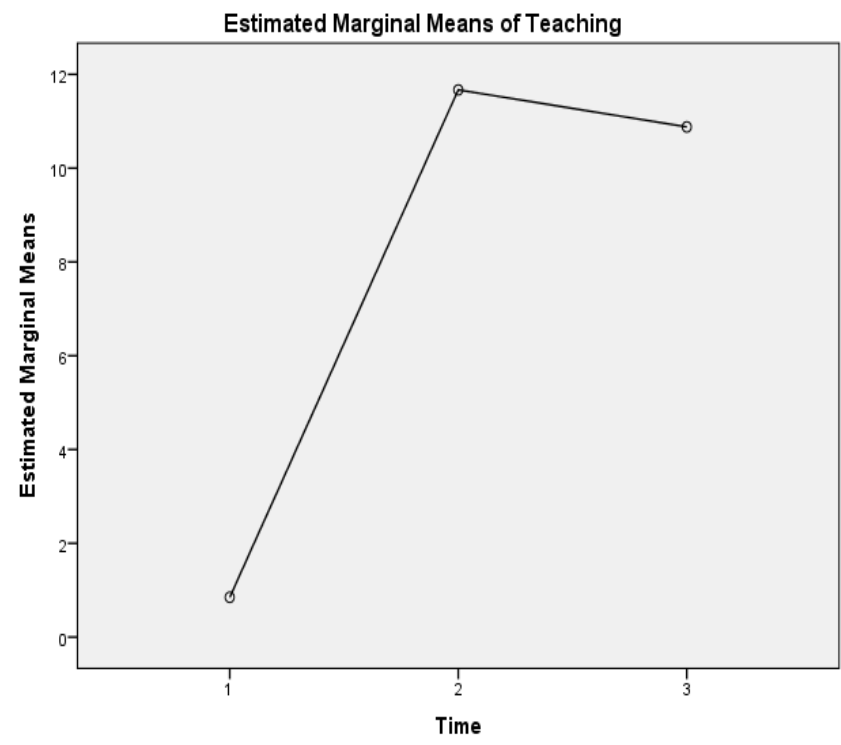

Figure 1. Diagram of estimated marginal means of grades of learning and retaining in pre-test (1), post-test (2) and delayed post-test (3)

The above figure shows the diagram of marginal means estimated of learning and retaining grades in pre-test(1), post-test(2) and delayed post-test(3). Regarding the diagram, it is distinguished that there is difference among means of learning and retaining words in the three tests (pre-test, post-test and delayed post-test); and language learners havenot done the same in every three test. This means teaching vocabulary to language learners is 
effective in their learning and retaining words.

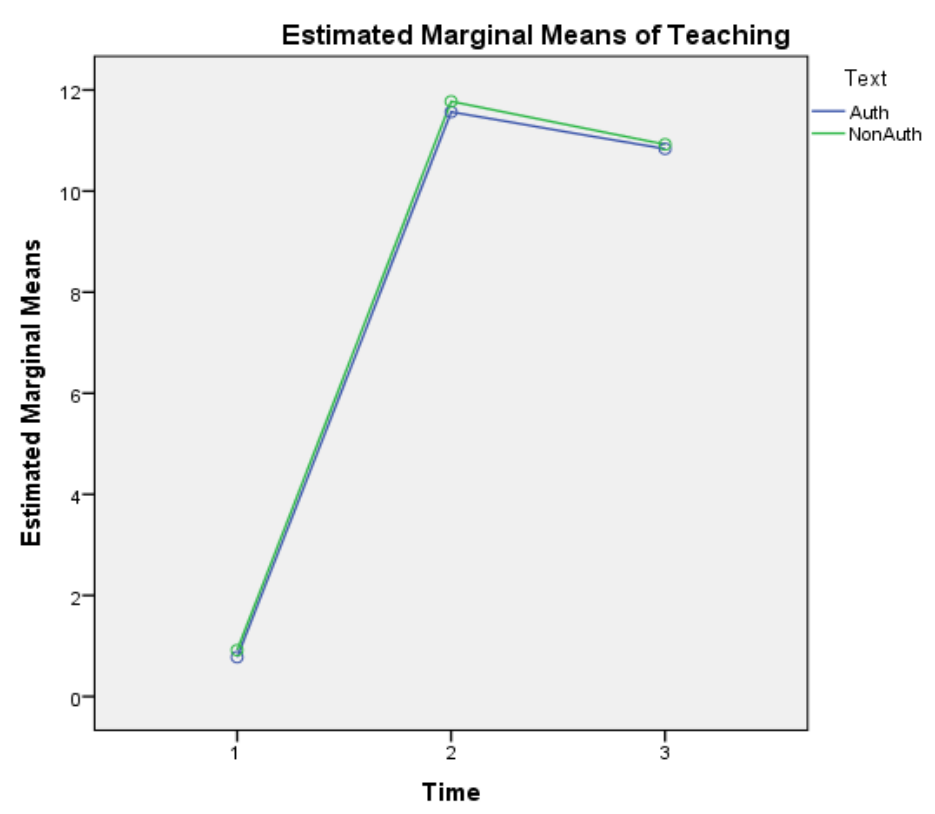

Figure 2. Linear diagram of estimated marginal means of learning and retaining grades of vocabulary at pre-test (1), post-test (2) and delayed post-test (3) taken by language learners, using authentic (blue) and non-authentic (green) texts

The above figure, shows linear diagram of estimated marginal means of vocabulary learning and retaining in pre-test (1), post-test (2) and delayed post-test (3) taken by language learners using authentic (blue) and non-authentic (green) texts. Regarding the lines drawn, it is realized that teaching words of authentic and non-authentic texts makes no different impact on language learning and retaining ability. This means that authentic and non-authentic texts have no considerable difference on improving Iranian EFL learners' vocabulary retention, indicating that the first hypothesis of the present research.

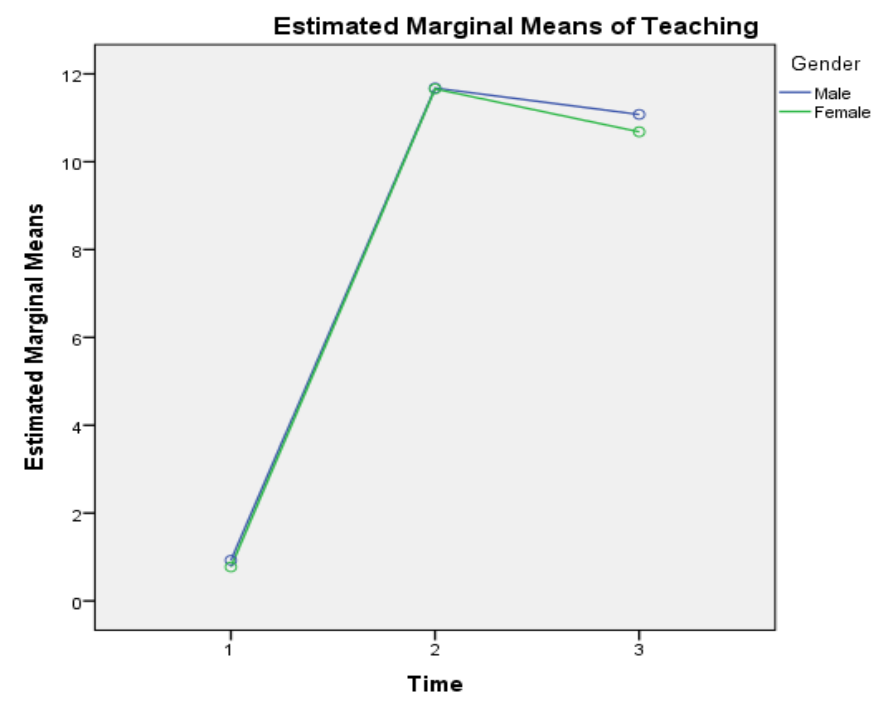

Figure 3. Diagram of estimated marginal means of vocabulary learning and retaining grades at pre-test (1), post-test (2) and delayed post-test (3) taken by male (blue) and female (green) language learners 
The above figure, shows the linear diagram of estimated marginal means of learning and retaining vocabulary grades of pre-test(1), post-test(2) and delayed post-test(3) taken by male(blue) and female(green) language learners. Regarding positions of the liens, it is realized that male learners in comparison with female ones have got no different performance. In other words, teaching vocabulary has equal effect on the ability of learning and retaining of male and female language learners. That is to say, female and male language learners present no difference in ability of learning and retaining vocabulary.
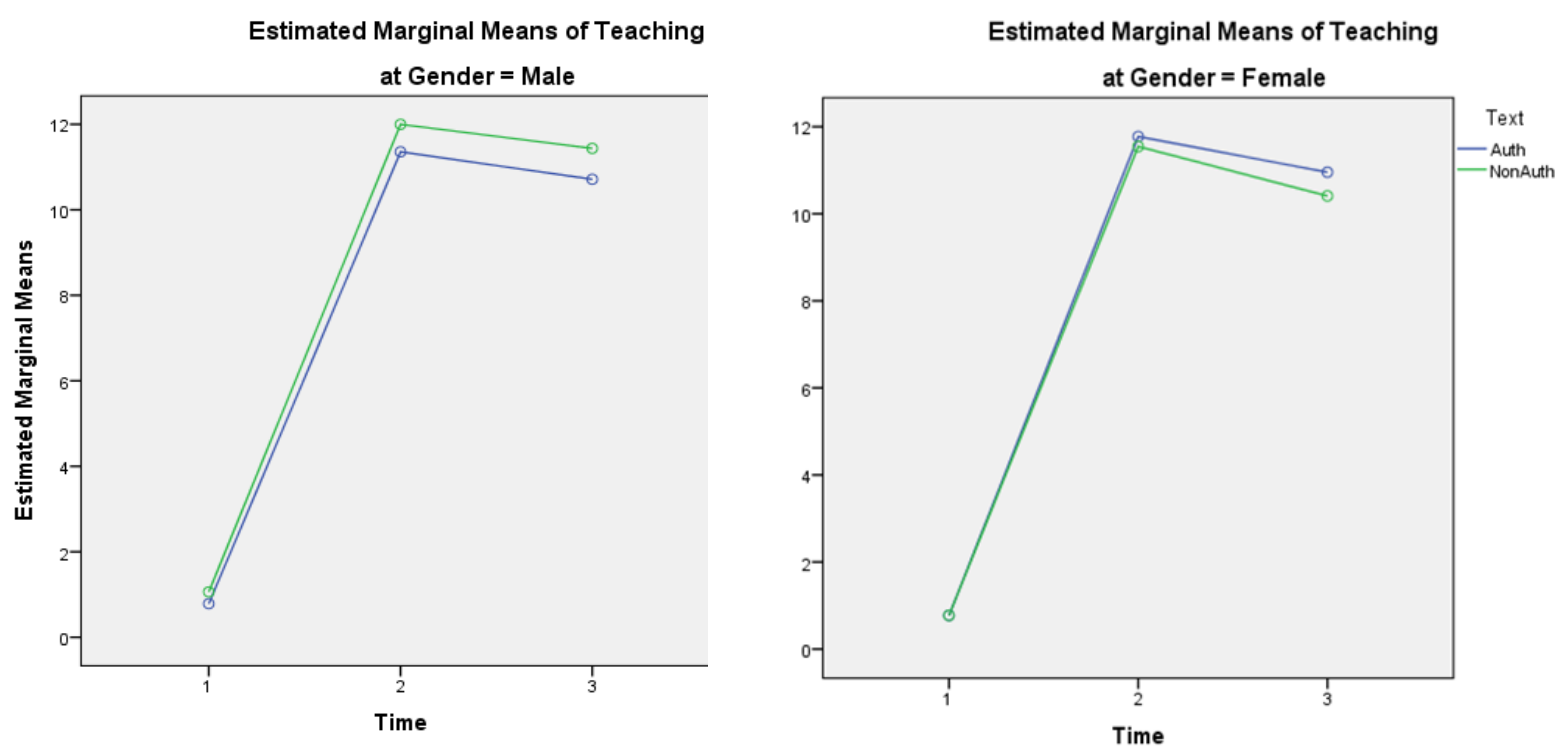

Figure 4. linear diagrams of estimated marginal means of learning and retaining vocabulary grades of pre-test (1), post-test (2) and delayed post-test (3) taken by male language learners (left diagram) and female (right diagram) in authentic (blue) and non-authentic (green)

Figure above, shows linear diagram of estimated marginal means of learning and retaining vocabulary grades of pre-test (1), post-test (2) and delayed post-test (3) taken by male language learners (left diagram) and female (right diagram) in authentic (blue) and non-authentic (green). According to the position of these lines, it is realized that learning and retaining ability of male and female language learners' vocabulary of authentic and non-authentic texts are similar. It means language learners' gender has no effect on learning and retaining vocabulary of authentic and non-authentic texts; ie, Iranian language learners' ability of learning and retaining authentic and non-authentic text vocabulary has no relation with their gender; that indicates accuracy of the second hypothesis of the present research.

\section{Conclusions}

According to the analyzed data of the study, there was not any significant difference between Iranian EFL learners' gender in vocabulary retention ability, whether the text is authentic or non-authentic. Also, the effect of authentic versus non-authentic texts on Iranian EFL learners' vocabulary retention ability is not significant. Furthermore, the study results show that learners' retention ability is actually improved after the treatment regardless of learners' gender and text types.

\section{Pedagogical Implications}

One of the goals of the present study was to investigate whether authentic texts have positive effect on EFL learner's vocabulary retention. So, learners have been exposed to an equal number of vocabularies and their meanings selected from both authentic and non-authentic texts. The results provided evidence that; no benefits attributed to vocabulary retention are accounted for by using authentic and non-authentic texts. Furthermore the genders of upper-intermediate Iranian EFL learners have no impact on their vocabulary retention regarding authentic versus non-authentic text. As a matter of fact, according to the findings of this study, text authenticity had not any significant effect on the vocabulary retention of the students.Foreign language teachers, especially those who teach in language institutes, benefit from this research. While teaching vocabulary, language teachers should 
focus on other factors rather than EFL learners gender and authentic versus non-authentic texts as there is no significant difference in using these two types.

Beside teachers, curriculum designers and test makers can benefit from this study's results as they can use both authentic and non-authentic texts regardless of learners' gender.

\section{References}

Adams, M. J. (2000). Beginning to read: Thinking and learning about print. Cambridge, MA: MIT Press.

Anderson, R. C., \& Freebody, P. (1981). Vocabulary knowledge. In J. T. Guthrie (Ed.), Comprehension and teaching: Research perspectives (pp. 77-117). Newark, DE: International Reading Association.

Berardo, S. A. (2006). The use of authentic materials in the teaching of reading. The Reading Matrix, 6(2), 60-69.

Brisbois, J. E. (1995). Connections between first-and second-language reading. Journal Reading Behavior, 27 , 565-584. Cervantes Virtual Center. http://dx.doi.org/10.1080/10862969509547899

Chomsky, N. (1965). Aspects of the theory of syntax. Cambridge: The Massachusetts Institute of Technology Press.

Geva, E., \& Clifton, S. (1994). The development of first and second language reading skills in early French immersion. The Canadian Modern Language Review, 50, 646-667.

Gilmore, A. (2007). Authentic materials and authenticity in foreign language learning.Language Teaching, 40(2), 97-118. http://dx.doi.org/10.1017/S0261444807004144

Groot, P. J. M. (2000). Computer assisted second language vocabulary acquisition. Language Learning \& Technology, 4(1), 60-81.

Hulstijn, J. H., Hollander, M., \& Greidanus, T. (1996). Incidental vocabulary learning by advanced foreign language students: The influence of marginal glosses, dictionary use, and reoccurrence of unknown words. The Modern Language Journal, 80, 327-339. http://dx.doi.org/10.1111/j.1540-4781.1996.tb01614.x

Khaniya, T. R. (2006). Use of authentic materials in ESL classrooms. Journal of NELTA, 11(2), 17- 23.

Kim, S. A. (1995). Types and sources of problems in L2 reading: A qualitative analysis of the recall protocols of Korean high school ESL students. Foreign Language Annuals, 28, 49-70. http://dx.doi.org/10.1111/j.1944-9720.1995.tb00769.x

Knight, S. (1994). Dictionary use while reading: The effects on comprehension and vocabulary acquisition for students of different verbal abilities. The Modern Language Journal, 78, 285-299. http://dx.doi.org/10.1111/j.1540-4781.1994.tb02043.x

Laufer, B. (1997). The lexical plight in second language reading: Words you don't know, words you think you know, and words you can't guess. In J. Coady, \& T. Huckin (Eds.), Second language vocabulary acquisition: A rationale for pedagogy (pp. 20-34). New York: Cambridge University Press.

Lomicka, L. (1998). To gloss or not to gloss: An investigation of reading comprehension online. Language Learning and Technology, 1 (4), 1-50.

Martinez, A. (2002). Authentic Materials: An Overview [online]. Mexico City: 2002. Retrieved from www3.telus.net/linguisticsissues/authenticmaterials.html

Mishan, F. (2005). Designing authenticity into language learning materials. Bristol: Intellect Books.

Nagy, W. E., \& Herman, P. A. (1988). Teaching vocabulary to improve reading comprehension. Newark, DE: International Reading Association.

Nation, I. S. P. (2001). Learning vocabulary in another language. Cambridge, UK: Cambridge University Press. http://dx.doi.org/10.1017/CBO9781139524759

Stahl, S. A. (1983). Differential word knowledge and reading comprehension. Journal of Reading Behavior, 15, 33-50. http://dx.doi.org/10.1080/10862968309547495

Stahl, S. A. (2003). Vocabulary and readability: How knowing word meanings affects comprehension. Topics in Language Disorders, 23(3), 241-248. http://dx.doi.org/10.1097/00011363-200307000-00009

Sweet, H. (1899). The practical study of languages. London: Oxford University Press. 


\section{Copyrights}

Copyright for this article is retained by the author(s), with first publication rights granted to the journal.

This is an open-access article distributed under the terms and conditions of the Creative Commons Attribution license (http://creativecommons.org/licenses/by/3.0/). 